\title{
Dual-Mode Combustion of a Jet in Cross-Flow with Cavity Flameholder
}

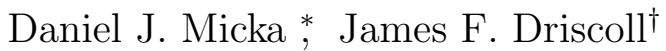 \\ University of Michigan, Ann Arbor, MI, 48109, USA
}

\begin{abstract}
The ignition and combustion stabilization location in a laboratory dual-mode ramjet/scramjet combustor was studied experimentally. The combustor consisted of a single hydrogen fuel jet injected normally into a supersonic crossflow upstream of a wall cavity pilot flame. Experiments were performed with Mach 2.2 and 2.5 nozzles at stagnation temperatures $\left(T_{0}\right)$ of $1050 \mathrm{~K}$ to $1400 \mathrm{~K}$, which correspond to flight Mach numbers of 4.3 to 5.2. High speed imaging of the flame luminosity resolved the ignition process which was found to begin in the wall cavity for all conditions. The lean ignition limit of the combustor was found to be a function of the cavity fueling rate. Increasing $\dot{m}_{\text {cavfuel }} / \dot{m}_{\text {totalfuel }}$ from 0.02 to 0.07 lowered the combustor lean ignition limit by approximately $15 \%$. For ramjet operation, two distinct combustion stabilization modes were found for main fuel injection a sufficient distance upstream of the cavity. At low $T_{0}$, the combustion was anchored at the leading edge of the cavity by heat release in the cavity shear layer. At high $T_{0}$, the combustion was stabilized a short distance downstream of the fuel injection jet in its wake. For an intermediate range of $T_{0}$, the reaction zone oscillated between jet-wake and cavity stabilized positions with intermediate locations being unstable. Wall pressure measurements showed that cavity stabilized combustion is the steadiest, followed by wake stabilized, and the oscillatory case. For fuel injection close to the cavity, the reaction zone locations for the two stabilization modes overlapped, and cavity fueling became an important factor in the steadiness of the flow field. Scramjet mode combustion was found to only exist in the cavity stabilized mode for the conditions studied.
\end{abstract}

\section{Nomenclature}

$\begin{array}{ll}f & \text { fraction of time combustion is stabilized in jet-wake mode } \\ H & \text { test section height in constant area section } \\ \dot{m}_{\text {cavfuel }} & \text { mass flow rate of cavity pilot fuel } \\ \dot{m}_{\text {totalfuel }} & \text { mass flow rate of total fuel (includes cavity and main fuel) } \\ M_{i, \text { entrance }} & \text { isolator entrance Mach number (equal to nozzle exit Mach number) } \\ M_{i, \text { exit }} & \text { isolator exit Mach number (equal to combustor entrance Mach number) } \\ M_{f l i g h t} & \text { flight Mach number } \\ \phi & \text { overall equivalence ratio }\left(\dot{m}_{\text {totalfuel }} / \text { stoichiometric } \dot{m}_{\text {totalfuel }} \text { ) }\right. \\ P_{w} & \text { wall static pressure } \\ P_{0, i} & \text { air stagnation pressure upstream of the nozzle } \\ \sigma_{P_{w} / P_{0, i}} & \text { standard deviation of static to stagnation pressure ratio } \\ T_{0} & \text { vitiated air stagnation temperature } \\ X_{H_{2} O} & \text { mole fraction of } H_{2} O \text { in vitiator products } \\ X_{\mathrm{O}_{2}} & \text { mole fraction of } \mathrm{O}_{2} \text { in vitiator products } \\ x & \text { axial location in test section measured from cavity leading edge } \\ (x / H)_{\text {crit }} & (x / H) \text { location of flamefront which separates jet-wake and cavity stabilized combustion } \\ (x / H)_{\text {mainfuel }} & (x / H) \text { location of main fuel injection } \\ y & \text { vertical location in test section measured from bottom wall (same side as cavity) }\end{array}$

\footnotetext{
${ }^{*}$ Graduate Student, Department of Aerospace Engineering, Member

${ }^{\dagger}$ Professor, Department of Aerospace Engineering, Fellow
} 


\section{Introduction}

Wall fuel jet injection with a cavity flameholder is a desirable configuration for a dual-mode scramjet combustor due to the low pressure drop and cooling requirements. ${ }^{1-3}$ The cavity recirculation zone provides a long residence time for the fuel and air to mix and burn. The cavity flame provides a source of heat and radicals to ignite and stabilize combustion in the main flow. The main fuel injection may be angled to recover some of the jet momentum or it may be normal to achieve maximum penetration. Of particular interest with this configuration is the ignition, combustion stabilization, and interaction of the main flow combustion with the cavity.

The aerothermodynamics of a dual-mode engine are quite complex and lead to significantly different flow conditions in the combustor for ramjet and scramjet operation. ${ }^{4-7}$ At low flight Mach numbers $\left(M_{\text {flight }}\right)$ the engine is operated in the thermally choked, ramjet mode. A pre-combustion shock train in the isolator slows the flow to subsonic speeds before the fuel is burned. A thermal throat in the diverging section of the combustor allows the exhaust to be re-accelerated to supersonic speeds. At higher $M_{\text {flight }}$, the precombustion shock train becomes weaker until the isolator exit Mach number $\left(M_{i, e x i t}\right)$ is supersonic and eventually the pre-combustion shock train is swallowed completely.

Since this type of engine produces no thrust at zero flight speed, it must be ignited after it is accelerated to its takeover speed by another propulsion system. This takeover speed will be dictated by a combination of efficiency and ignition considerations and will define the lowest Mach number at which the engine operates. At this relatively low $M_{\text {flight }}$, the incoming $T_{0}$, and thus the maximum $\phi_{\max }$ before unstart, will be lower than at higher $M_{\text {flight }}$. Both these factors make ignition difficult at the takeover speed. With no main flow combustion, there is no pre-combustion shock train in the isolator, so the flow in the combustor is supersonic before ignition. Thus static temperature, pressure, and residence time in the combustor are all significantly lower before ignition than after. Therefore the ignition and combustion stabilization can be considered to be significantly different problems in a dual-mode scramjet combustor. In this study, the ignition sequence is observed and explained from high speed movies. Additionally, the lean ignition limit is measured as a function of the cavity fueling rate.

The combustion stabilization mechanism is also of importance in a dual-mode combustor. Even with a pre-combustion shock train, the combustor temperature is insufficient to provide consistent auto-ignition at low $M_{\text {flight }}$. There must exist a location of favorable equivalence ratio, temperature, and pressure where the reaction base can stabilize and serve as a source of heat and radicals. ${ }^{1}$ The combustion must be stabilized over a wide range of conditions including ram-to-scram mode transition when a strong shock train is swallowed and the static temperature and pressure in the combustor drop abruptly. At very high $M_{\text {flight }}$ (largest $T_{0}$ ), the temperature in the combustor will become high enough for auto-ignition. Through all these different regimes, the combustion stabilization location and mechanism may change.

The dual-mode combustion problem that is studied is shown in Fig. 1. A supersonic vitiated flow at $T_{0}=1050-1400 \mathrm{~K}$ enters a constant area isolator which may contain a pre-combustion shock train. For ramjet mode operation there is a strong pre-combustion shock train (as shown in Fig. 1) with a subsonic $M_{i, e x i t}$. For scramjet mode operation, there is a weak pre-combustion shock train with a supersonic $M_{i, e x i t}$. A single sonic jet of hydrogen fuel is injected perpendicular to the flow upstream of a wall cavity. Fuel may also be injected directly into the wall cavity to create a pilot flame. This simple laboratory combustor employs basic flow elements that have been proposed for practical dual-mode combustors such as sonic wall fuel injection and a wall cavity flameholder. Therefore it is expected to exhibit combustion stabilization and ignition properties which are applicable to this type of combustor in general.

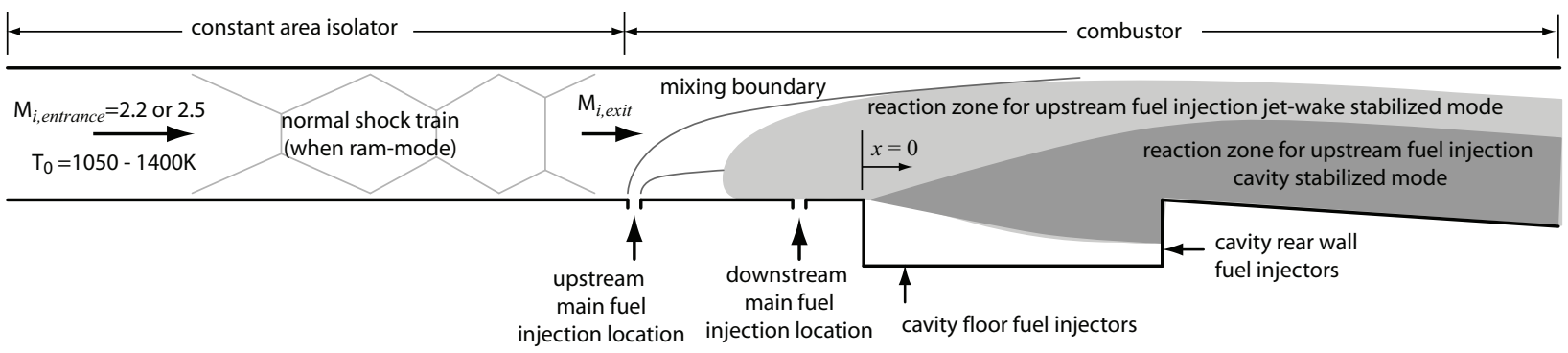

Figure 1. Drawing of test section with flow features for ramjet mode combustion. 
Previous studies have focused on combustors with similar features to the one used for the current study, ${ }^{1,2,8-17}$ but the combustion stabilization mechanism and the role of the cavity is still not fully understood. Mathur ${ }^{2}$ and Lin $^{11}$ have studied an ethylene fueled combustor with angled fuel injection upstream of a cavity at $T_{0}=1000-1300 K, M_{i, e n t r a n c e}=1.8$ and have shown that the reaction zone is anchored at the leading edge of the cavity and spreads into the flow at an approximately constant angle. For very high temperature flows, it has been found that fuel may auto-ignite downstream ${ }^{8,9}$ or even upstream $^{18}$ of a fuel jet injected normally into a supersonic crossflow with no flameholder. The current study focuses on combustion stabilization for conditions where auto-ignition is not expected to be dominant. Ramjet mode combustion stabilization was studied for temperatures equivalent to $M_{\text {flight }}$ of 4.3 to 5.2 , which is near the low end of where dual-mode combustors are expected to operate. Two distinct combustion stabilization modes are found under these conditions, each of which have different implications for combustor design. The combustion stabilization also was examined for one case of scramjet mode operation.

\section{Experimental Setup}

Experiments were performed in the supersonic combustion facility at the University of Michigan. Both a Mach 2.2 and Mach 2.5 test section were used, which were identical except for the isolator length. The isolator length was defined to be the distance from the nozzle exit to the first fuel injection port. It measured $359 \mathrm{~mm}$ for the Mach 2.2 test section and $140 \mathrm{~mm}$ for the Mach 2.5 test section. A schematic of the Mach 2.2 test section is shown in Fig. 2. A two dimensional nozzle is followed by a constant area isolator with a cross section of $25.4 \mathrm{~mm}$ by $38.1 \mathrm{~mm}$. This constant area section extends $402 \mathrm{~mm}$ until the leading edge of a rectangular cavity $50.8 \mathrm{~mm}$ long and $12.7 \mathrm{~mm}$ deep, which spans the width of the test section. At the rear edge of the cavity begins a $349 \mathrm{~mm}$ long 4 degree diverging section which dumps into a 152 mm diameter exhaust. Hydrogen fuel was injected sonically through a round port at either $43.2 \mathrm{~mm}$ or $14.0 \mathrm{~mm}$ upstream of the cavity leading edge $\left((x / H)_{\text {mainfuel }}=-1.70\right.$ or -0.55$)$. A 2.18 or $2.49 \mathrm{~mm}$ diameter injection hole could be used at either location depending on the desired fuel flow rate for the test. Previous work on sonic jet injection into supersonic crossflow has shown the penetration distance to be relatively independent of injection hole diameter for a fixed mass flow ${ }^{19,20}$ (especially for two holes of such similar size). The two ports were never used simultaneously. Hydrogen fuel was used for its fast kinetics, which allow it to mimic more practical hydrocarbon fuels at somewhat higher temperatures. Pilot fuel could be directly injected into the cavity through three spanwise $1.19 \mathrm{~mm}$ diameter ports on the cavity floor or rear wall. Previous studies have found different flame structures and stability properties by fueling the cavity from different locations. ${ }^{3,21-23}$ A spark plug in the cavity floor was used to ignite the cavity flame. Fused silica windows $305 \mathrm{~mm}$ long allowed imaging of the combustion region. Two sets of smaller windows in the isolator allow imaging of the pre-combustion shock train. There are 42 static pressure ports in the combustor walls and window blanks. Only eight locations were monitored in the present study.

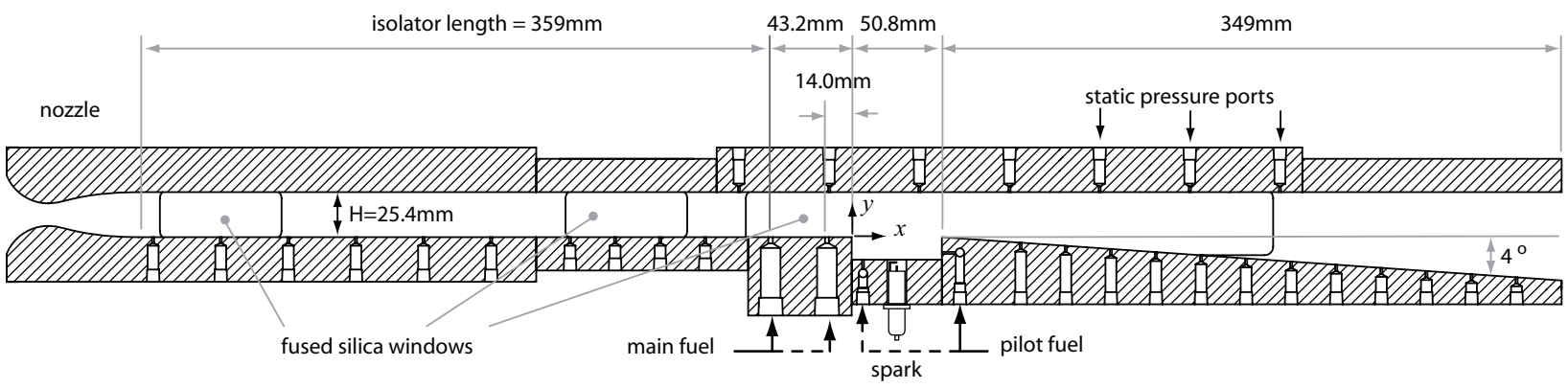

Figure 2. Diagram of Mach 2.2 test section

The range of flow conditions explored in this study is given in Table I. An electric heater heated the air to $450 \mathrm{~K}$. A hydrogen fueled vitiator then raised $T_{0}$ to $1050-1400 \mathrm{~K}$. Make-up oxygen was added to maintain a $0.21 \mathrm{O}_{2}$ mole fraction in the vitiator products. The run times were kept under 10 seconds in order to prevent thermal damage to the uncooled combustor. Therefore all the flow control and data acquisition equipment was automated and controlled by a Labview program. The timing for each run is shown in Fig. 3. The vitiator oxygen was controlled by a Brooks $5853 \mathrm{~S}$ thermal mass flow controller. The vitiator and cavity fuel 
were controlled by solenoid valves and metered by choked orifices. The main hydrogen fuel was controlled by a Parker EPDN proportional valve and reached $95 \%$ of its final pressure $200 \mathrm{~ms}$ after being triggered.

\begin{tabular}{ccc}
\hline Parameter & Mach 2.2 Test Section Conditions & Mach 2.5 Test Section Conditions \\
\hline \hline$P_{0, i}$ & $590 \pm 15 \mathrm{kPa}$ & $590 \pm 15 \mathrm{kPa}$ \\
vitiated air $T_{0}$ & $1050-1400 \mathrm{~K}$ & $1250-1400 \mathrm{~K}$ \\
fuel $T_{0}$ & $288 \mathrm{~K}$ & $288 \mathrm{~K}$ \\
$\phi$ & $0.18-0.32$ & $0.20-0.43$ \\
$\dot{m}_{\text {cavfuel }} / \dot{m}_{\text {totalfuel }}$ & $0-0.12$ & $0-0.25$ \\
$(x / H)_{\text {mainfuel }}$ & $-1.70,-0.55$ & $1.70,-0.55$ \\
main fuel injector diameter & $2.18,2.49 \mathrm{~mm}$ & $2.18,2.49 \mathrm{~mm}$ \\
main fuel injection $P_{0}$ & $690-1090 \mathrm{kPa}$ & $690-1090 \mathrm{kPa}$ \\
cavity fuel injection location & rear wall, floor, both & rear wall, floor, both \\
vitiated air $\mathrm{X}_{\mathrm{H}_{2} \mathrm{O}}$ & $0.11-0.21$ & $0.17-0.21$ \\
vitiated air $\mathrm{X}_{\mathrm{O}_{2}}$ & 0.21 & 0.21 \\
\hline
\end{tabular}

Table 1. Test conditions

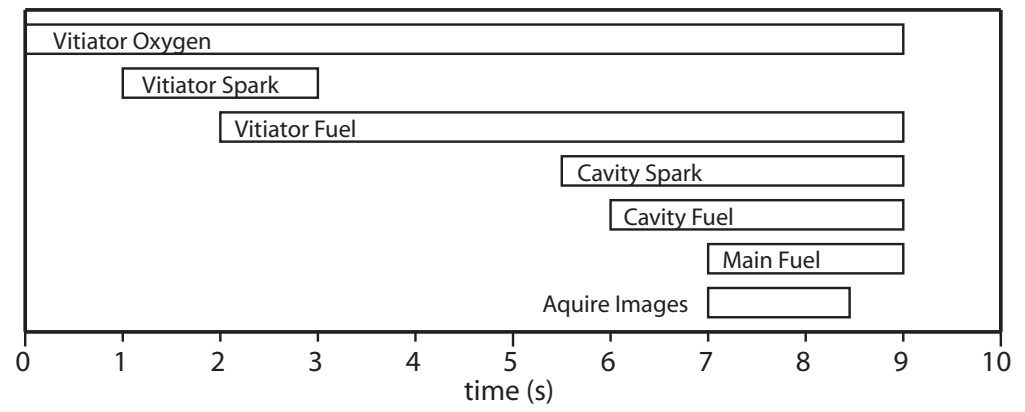

Figure 3. Vitiator and combustor flow timing

For each run, the static pressure was measured at eight locations in the combustor and isolator by Cooper PTG 403 pressure transducers and recorded at $40 \mathrm{~Hz}$. This data was used to detect that main flow combustion had occurred, determine the strength and location of the pre-combustion shock train, and estimate the steadiness of the flow field. A Vision Research Phantom 9.0 camera was used for high speed imaging of the flame luminosity. Movies of 864 by 280 pixels were acquired at $7100 \mathrm{~Hz}$ in the Mach 2.5 test section and 960 by 288 pixels at $4000 \mathrm{~Hz}$ in the Mach 2.2 test section. The field of view was $\sim 150 \mathrm{~mm}$ in length and spanned the height of the test section and cavity.

The air stagnation temperature was measured by a K-type thermocouple in the settling chamber just upstream of the nozzle. The temperature generally increased by $\sim 50 K$ during the 2 seconds the main fuel was on during each run. The average temperature measured during this time is reported as the nominal value of $T_{0}$.

\section{Results and Discussion}

\section{A. Ignition}

The ignition data presented was taken in the Mach 2.5 test section unless otherwise stated. The shorter isolator in the Mach 2.5 test section was not a detriment for the ignition tests since the pre-combustion shock train does not exist before ignition. Ignition is defined here to be the condition where combustion first appears in the main flow. It was found that for all conditions there was a step change in the wall pressure over the cavity (indicating a step change in the amount of fuel burning) when main flow ignition was achieved. Before ignition, fuel would burn only in the cavity and boundary layer behind it. This led to wall static pressures $\left(P_{w}\right)$ at $x / H=-0.50$ of less than $0.15 P_{0, i}$. At ignition, the reaction zone moved significantly 
out into the main flow, which for virtually all conditions was sufficient to thermally choke the flow. This caused a strong pre-combustion shock train (ramjet mode operation) with $P_{w} \approx 0.4 P_{0, i}$ at the same location. For the few cases of scramjet mode ignition, the combustion induced pressure rise at this location was still $P_{w}>0.25 P_{0, i}$. Thus ignition is defined for this combustor to have occurred when $P_{w}>0.25 P_{0, i}$ on the top wall at $(x / H)=-0.50$.

Experiments were undertaken to examine the effect of the cavity on ignition. The parameters varied were: 1) the main fuel injection location 2) the fraction of total fuel directly injected into the cavity $\left(\dot{m}_{\text {cavfuel }} / \dot{m}_{\text {totalfuel }}\right)$ and 3$)$ the location of the cavity fuel injection. It was found that of these parameters, $\dot{m}_{\text {cavfuel }} / \dot{m}_{\text {totalfuel }}$ had the greatest effect on the lean ignition limit of the combustor. The effect of the main fuel injection location and cavity fuel injection location was initially found to be small and thus not systematically explored. Figure 4 shows how the lean ignition limit varied with cavity fueling rate for upstream main fuel injection $\left((x / H)_{\text {mainfuel }}=-1.70\right)$ with $T_{0}=1355 K \pm 35 K$. It can be seen that the minimum $\phi$ for ignition drops significantly as $\dot{m}_{\text {cavfuel }} / \dot{m}_{\text {totalfuel }}$ is increased from 0.02 to 0.07 . As $\dot{m}_{\text {cavfuel }} / \dot{m}_{\text {totalfuel }}$ is further increased from 0.07 to 0.21 , the ignition limit change is small. The same trend was observed for downstream main fuel injection. Larger rates of direct cavity fueling were not explored due to flow rate limitations of the cavity fueling hardware. Such very large values of cavity fueling are expected to be of less interest for practical dual-mode combustors due to the detrimental effect on the penetration of the main fuel jet.

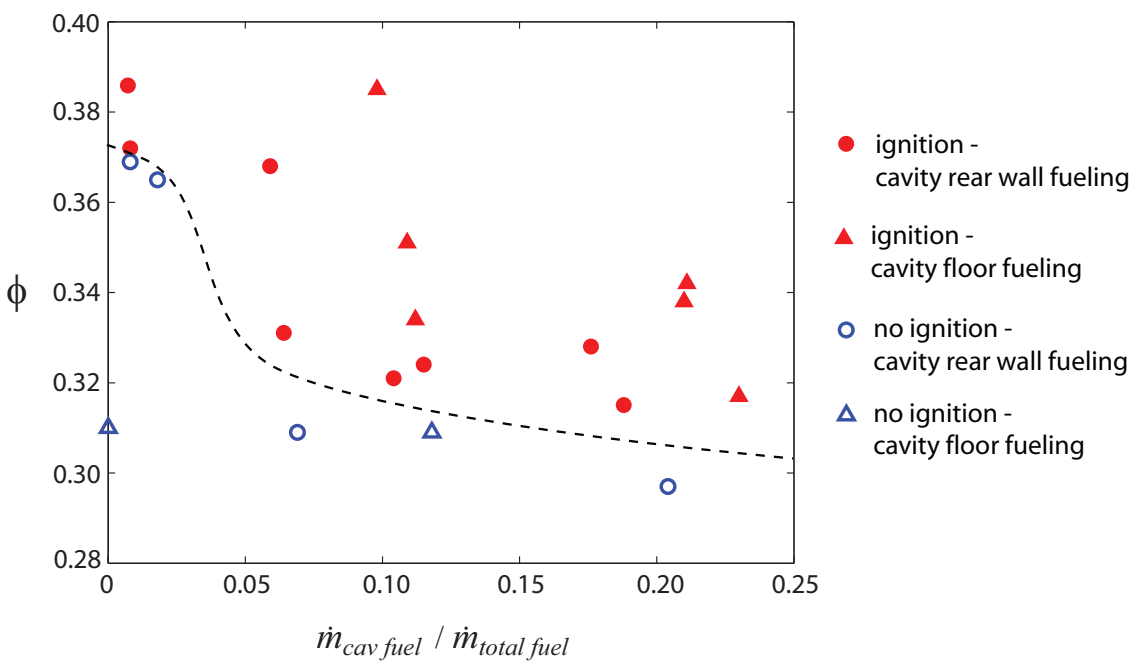

Figure 4. Cavity fueling rate effect on ignition limit. Mach 2.5 test section, upstream main fuel injection, $T_{0}=1355 K \pm 35 K$.

The high speed movies yield insight into the ignition process. In all cases observed, the main flow ignition started with reaction in the cavity. Figure 5 shows some flame luminosity images at important steps in the ignition process in the Mach 2.5 test section. (Note that in these figures there is a region of high intensity in the rear corner of the cavity due to a glowing sealant that is blacked out in the image. This overexposed the camera and caused an artificial vertical line of brightness to appear above the cavity rear wall that is not due to flame luminosity.) The time given for each image is the time after the main flow fuel was first triggered. The main fuel pressure reached $95 \%$ of its maximum value $200 \mathrm{~ms}$ after it was triggered and so is approximately constant during the sequence shown in Fig. 5 .

For each ignition event, a vigorous reaction first develops in the cavity as observed by high luminosity. The high heat release in the cavity acts as a blockage to the flow. This deflects the shear layer into the freestream which increases the blockage of the flow, strengthens the pre-combustion shock train, and thus raises the freestream static temperature and pressure. Thus the shear layer conditions become more conducive to combustion and the reaction spreads further. This causes additional blockage, allowing the reaction to again extend further into the flow in areas that previously could not sustain combustion. Figures 5(a)-(c) show flame luminosity images for this process. Eventually there is enough heat release that the flow becomes thermally choked. At this point, a strong shock train forms upstream of the reaction zone and the ignition process is complete. If the fuel is injected from the upstream location, as in Fig. 5, the combustion may 


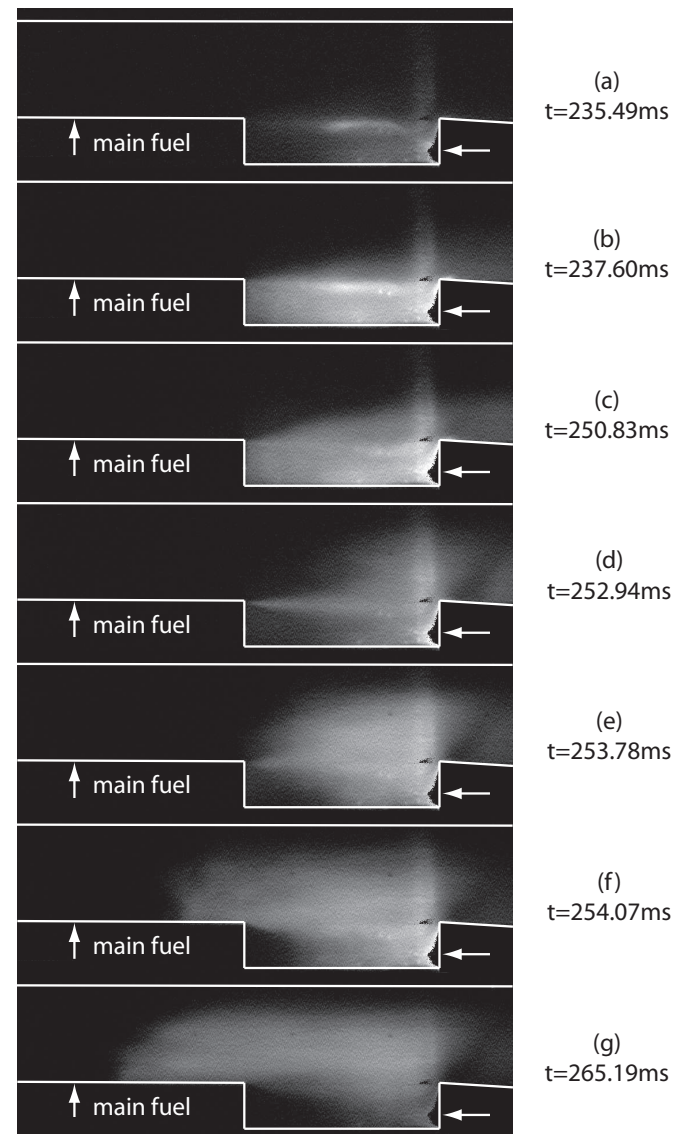

Figure 5. Ignition sequence flame luminosity. Time given from main fuel trigger. Mach 2.5 test section, upstream main fuel injection, $T_{0}=1350 \mathrm{~K}$, $\phi=0.34, \dot{m}_{\text {cavfuel }} / \dot{m}_{\text {total fuel }}=0.07$. Vertical white streak above cavity trailing edge in all pictures is an artifact of camera overexposure and is not combustion luminosity.

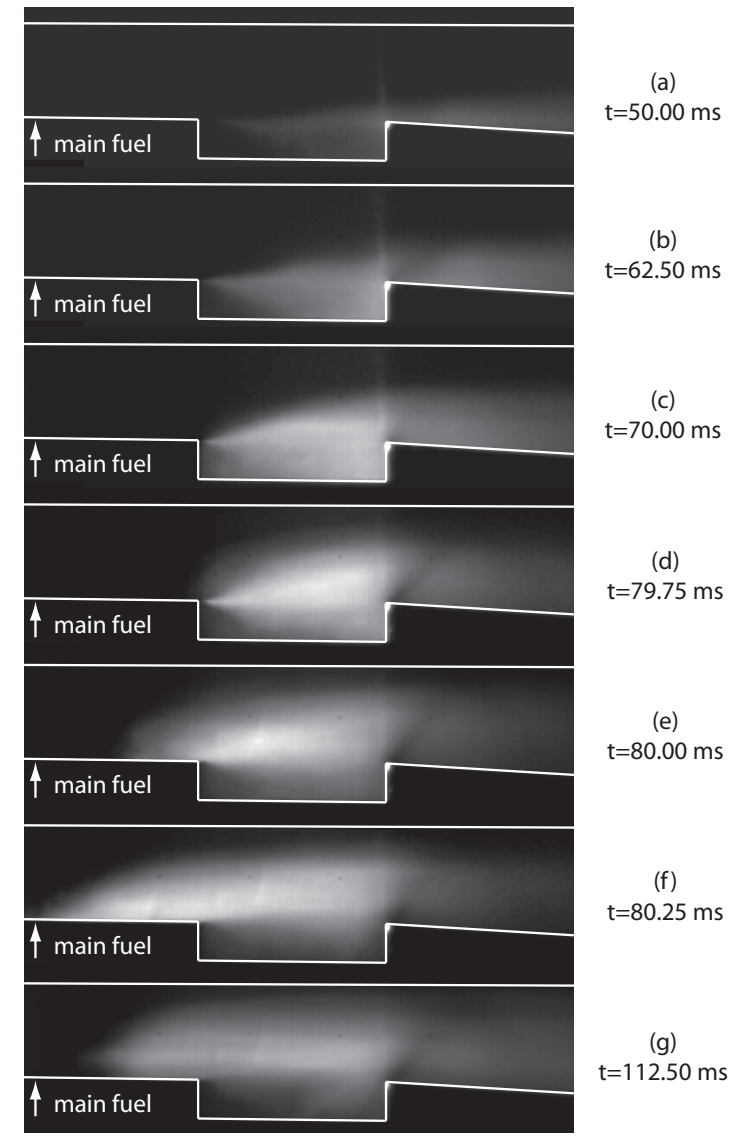

Figure 6. Ignition sequence flame luminosity. Time given from main fuel trigger. Mach 2.2 test section, upstream main fuel injection, $T_{0}=1370 \mathrm{~K}$, $\phi=0.26, \dot{m}_{\text {cavfuel }} / \dot{m}_{\text {totalfuel }}=0.0$.

flash forward from the cavity to the jet-wake stabilized location as discussed in Section B1. Figures 5 (d)-(f) show this process. Figure $5(\mathrm{~g})$ shows the combustion a short time after the ignition sequence in its "steady state" position stabilized in the wake of the fuel jet. The ignition process shown in Fig. 5 was near the lean ignition limit and took approximately $18 \mathrm{~ms}$ from the first appearance of a vigorous cavity reaction to the flame flashing forward to the jet-wake. For cases further from the ignition limit in the Mach 2.5 combustor, the ignition process was up to 5 times faster for the conditions studied. The basic process shown, though, is the same as was observed for all cases regardless of $T_{0}, \phi, \dot{m}_{\text {cavfuel }} / \dot{m}_{\text {mainfuel }}$, or fuel injection location.

A very similar process was observed in the Mach 2.2 test section. A major difference is that ignition process generally started while the main fuel pressure was still ramping up in the Mach 2.2 test section, while in the Mach 2.5 test section the main fuel pressure was usually above $90 \%$ of its final value when the process started. Figure 6 shows a typical ignition event in the Mach 2.2 combustor. This event takes longer than that shown in Fig. 5 because it is dependent on the fuel ramp time, but it is interesting to see that the sequence looks quite similar.

\section{B. Combustion Stabilization}

Unless otherwise noted the combustion stabilization results presented were taken in the Mach 2.2 test section. Compared with the Mach 2.5 test section, there was a much wider range of conditions in the Mach 2.2 test section for which: a) ignition was achieved due to the lower Mach number (higher static temperature and 
combustor residence time) and b) the pre-combustion shock train was contained in the isolator due to its greater length. For all cases presented, the shock train was contained in the isolator as is desirable in an operational engine. Cases for which the shock train was not contained set the upper $\phi$ limit for this combustor at the conditions tested. All cases tested in the Mach 2.2 test section yielded ramjet mode ( $\operatorname{subsonic} M_{i, \text { exit }}$ ) operation. $M_{i, \text { exit }}$ was computed to be between 0.68 and 0.82 from $P_{w} / P_{0, i}$ measured at $x / H=-3.25$ and using the $1-D$ method given by Heiser and Pratt. ${ }^{4} 5$ Scramjet mode (supersonic $M_{i, \text { exit }}$ ) operation was demonstrated in the Mach 2.5 test section. The higher Mach number in this combustor allowed more heat to be added to the flow before the onset of thermal choking (and thus scram-to-ram transition).

\section{Ramjet Mode Combustion - Upstream Fuel Injection}

The combustion in the Mach 2.2 test section with upstream fuel injection, $(x / H)_{\text {mainfuel }}=-1.70$, was studied for the full range of flow conditions given in Table I. All conditions tested achieved main flow ignition. The pre-combustion shock train was contained in the isolator for $\phi \lesssim 0.26$. Only data for cases in which the shock train was fully contained in the isolator is presented.

It was found that there were two distinct modes of main flow combustion stabilization. The average flame luminosity for these two combustion stabilization modes can be seen in Fig. 7. In the cavity stabilized combustion mode, the reaction zone is anchored at the leading edge of the cavity and spreads into the main flow at an approximately constant angle. In the jet-wake stabilized mode, the reaction zone is stabilized well upstream of the cavity in the wake of the fuel injection jet and the leading edge is curved. The cavity stabilized combustion mode appears similar to that found by Mathur ${ }^{2}$ and Lin, ${ }^{11}$ while the jet-wake stabilized combustion mode appears similar to that found by $\mathrm{Yu}^{9}$ The combustion was virtually always clearly stabilized in one location or the other, with combustion in other locations being very unstable.

The bimodal nature of the combustion is illustrated by Fig. 8. For this figure, 22500 total images were analyzed for 5 runs with $\phi=0.21, \dot{m}_{\text {cavfuel }} / \dot{m}_{\text {total fuel }}=0.02$ (rear wall injection), and $T_{0}=1130 K-1400 K$. An isoluminosity contour characteristic of the reaction zone leading edge was defined. Then the average axial location of this contour from $y / H=0.1-0.4$ was calculated for each image and plotted. From this histogram, it can be seen that there are two distinct regions where the flame can be stabilized. The upstream peak represents the jet-wake stabilized mode and the downstream peak represents the cavity stabilized mode. Even for run conditions where the combustion oscillated between the two stabilization locations, the distinct modes were clear. The combustion would generally oscillate between modes at low frequency, 5-20Hz, while the unstable transition time was only a few milliseconds.

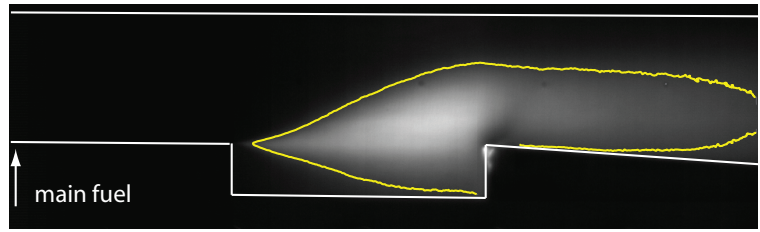

(a) Cavity stabilized combustion.

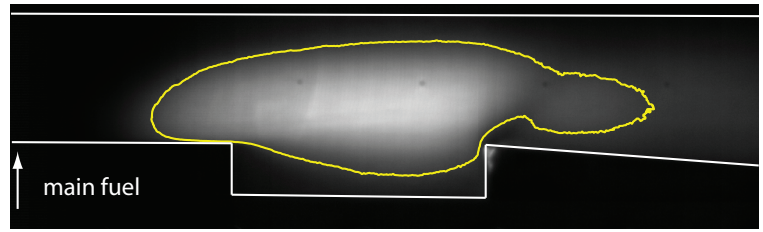

(b) Jet-wake stabilized combustion.

Figure 7. Flame luminosity images averaged over $75 \mathrm{~ms}$ during same run. $\phi=0.24, T_{0}=1250 \mathrm{~K}$, no cavity fueling. Yellow line is isoluminosity contour.

It was helpful to calculate the percent of time the combustion was stabilized in each of the two modes for different run conditions. This was done using the same definition of reaction zone leading edge as in Fig. 8 and setting a critical axial location which separates the two modes of $(x / H)_{\text {crit }}=0.4$. Each image where the average reaction zone leading edge was upstream of this value was considered to be in the jet-wake stabilized mode, downstream of this value in the cavity stabilized mode. The fraction of time in each mode was not very sensitive to the selection of $(x / H)_{\text {crit }}$ due to the small percent of time spent in transition. The results for runs with three combinations of $\phi$ and $\dot{m}_{\text {cavfuel }} / \dot{m}_{\text {totalfuel }}$ (all rear wall cavity fueling) for $T_{0}=1050 \mathrm{~K}-1400 \mathrm{~K}$ are plotted in Fig. 9. It can be seen that for the range of conditions explored, $T_{0}$ is the dominant variable in determining the combustion stabilization mode. At high $T_{0}(\gtrsim 1350 \mathrm{~K})$, the combustion was virtually always stabilized in the jet-wake mode. For low $T_{0}(\lesssim 1150 \mathrm{~K})$, the combustion was virtually never stabilized in the jet-wake mode, i.e. it was always stabilized in the cavity mode. There was a range of 


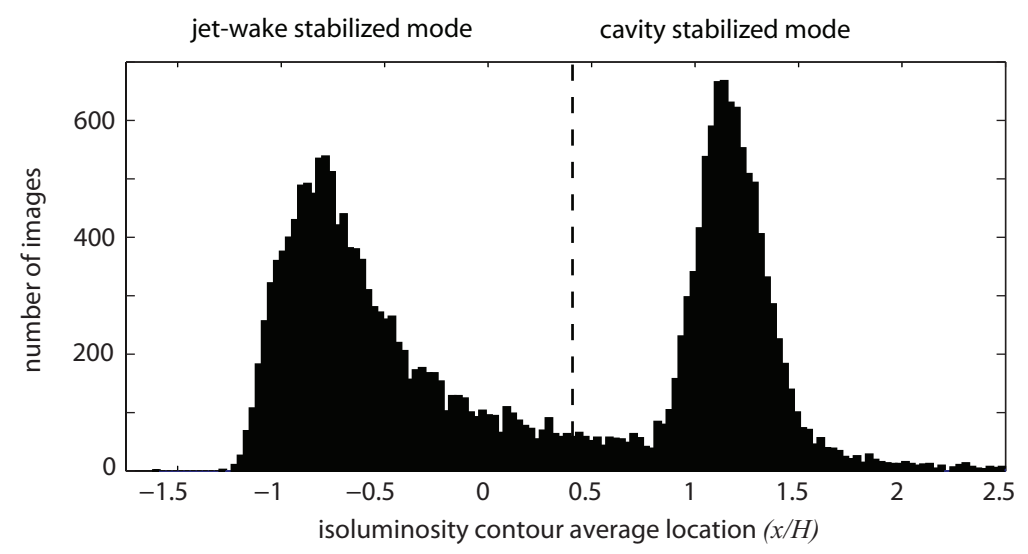

Figure 8. Histogram of isoluminosity contour axial locations for five runs with 22500 images total. $\phi=0.21$, $\dot{m}_{\text {cavfuel }} / \dot{m}_{\text {totalfuel }}=0.02, T_{0}=1130 \mathrm{~K}-1400 \mathrm{~K}$.

intermediate $T_{0}$ where the combustion oscillated between the two stabilization modes. The fraction of time in the jet-wake stabilized mode $(f)$ may be approximated by Eq. 1 for all conditions. Eq. 1 is plotted as a dashed line in Fig. 9.

$$
f \approx \frac{1}{2}+\frac{1}{2}\left|T_{0}-1250 K\right| \operatorname{erf}\left(\frac{T_{0}-1250 K}{75 K}\right)
$$

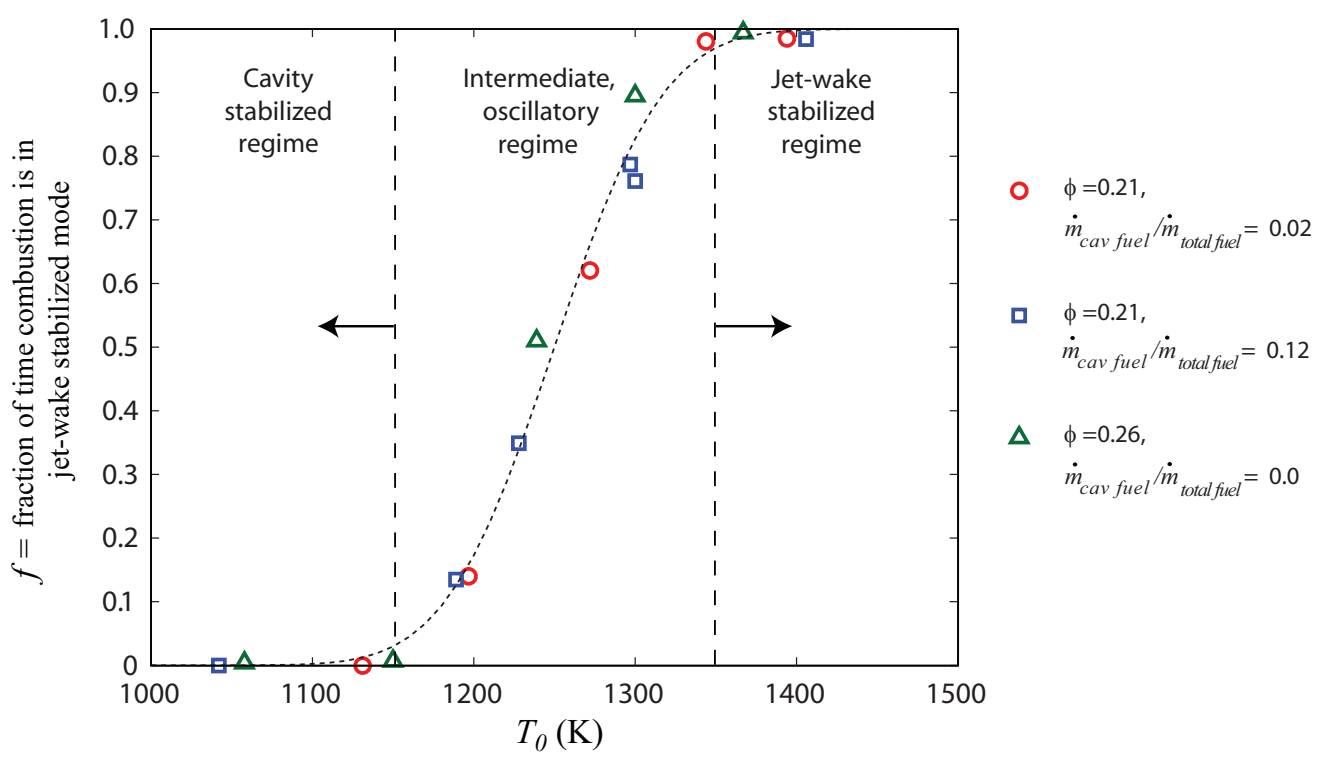

Figure 9. Combustion stabilization mode vs. $T_{0}$ for upstream fuel injection

The observed behavior may be explained in the following way. Cavity fueling rate does not play a role in the stabilization location because the cavity appears to be capable of stabilizing the combustion at all conditions studied. If the jet-wake stabilization location was not available, the cavity stabilization would always be sufficient, regardless of $\dot{m}_{\text {cavfuel }} / \dot{m}_{\text {totalfuel }}$. For cases when a jet-wake location is sufficient for stabilization, the flame is often not capable of flashing forward through the intermediate region (between the cavity and jet-wake stabilized locations) which has higher average velocity than the jet-wake stabilization location. At lower $T_{0}$, the flame remains in the cavity stabilized location shown in $7(\mathrm{a})$ until a fluctuation in the jet-wake occurs which is large enough to allow the flame to flash forward to a relatively stable location in the wake such as shown in $7(\mathrm{~b})$. The flame will then remain in the jet-wake stabilized location until another fluctuation makes the position unstable and it flashes back to the cavity stabilized location. As $T_{0}$ increases,

$$
8 \text { of } 13
$$


the flames speed increases. Thus the magnitude of the fluctuations required for the flame to flash forward to the jet-wake location become smaller, and the magnitude of the fluctuations which cause it to flash back become larger. Therefore, the flame spends more and more time in the jet-wake stabilized location as $T_{0}$ increases. At a high enough $T_{0}$, there are no fluctuations present in the flow which are sufficient to cause the jet-wake location to become unstable.

Figure 9 also shows that $\phi$ had little effect on the combustion stabilization mode for the conditions studied. For these very lean conditions, it is expected that the local equivalence ratio at the stabilization location in the jet-wake is near unity, and not close to $\phi$ overall. Thus, increasing $\phi$ for the conditions studied serves only to increase the size of the wake slightly, which could make the flame a little more likely to be stabilized in this location. The data in Fig. 9 does show this trend, but it could be within the noise of the data.

There is a large difference in the steadiness of the combustion between the different stabilization modes. This is apparent from the wall pressure data and the flame images. Figure 10 shows the standard deviation of the wall pressure at the eight measured locations in the isolator and combustor. Only low frequency fluctuations of the pressure were measured. The pressure is a marker of the steadiness of the combustion in a thermally choked flow because any change in heat release rate or distribution will cause a change in the pre-combustion shock train length and pressure rise. The highest values of $\sigma_{P_{w} / P_{0}, i}$ occur in the isolator due to the nature of the shock train. It is assumed that changes in the combustion are driving the unsteadiness in the pressure field, which is likely a coupled process.

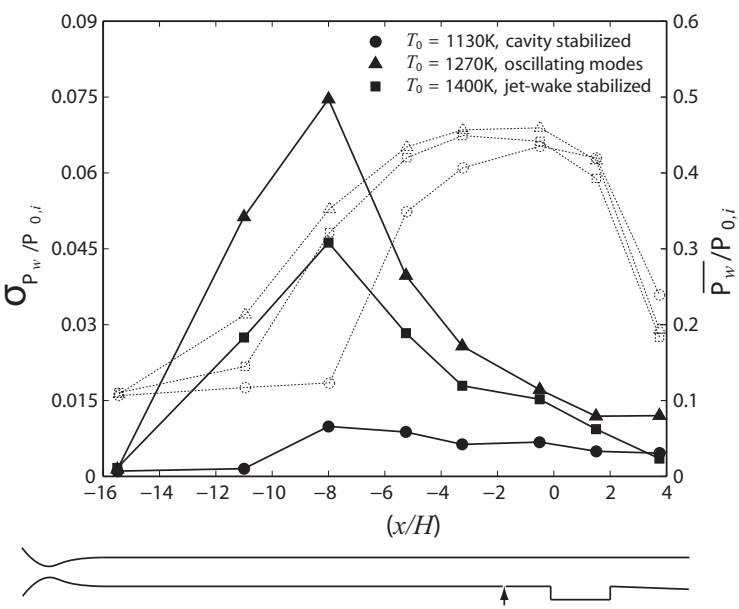

(a) $\phi=0.21, \dot{m}_{\text {cavfuel }} / \dot{m}_{\text {totalfuel }}=0.02$

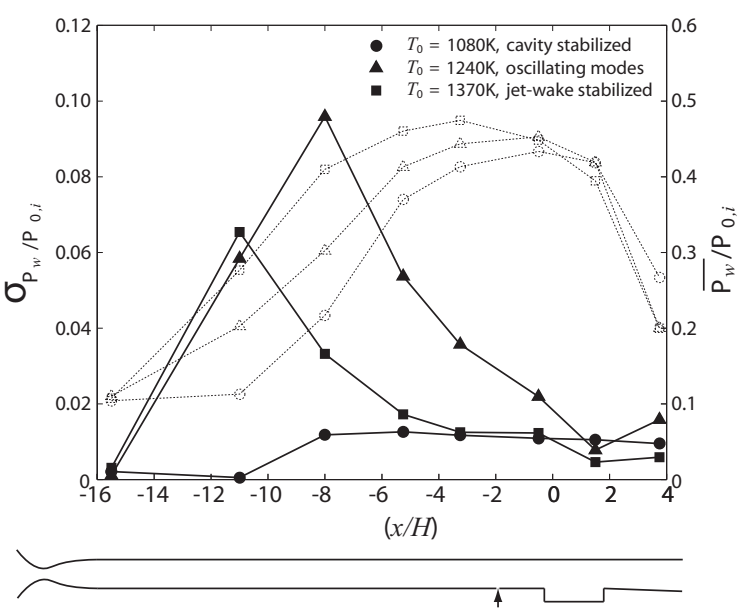

(b) $\phi=0.26$, no cavity fueling

Figure 10. Wall pressure standard deviation (solid symbols) and average (open symbols) for upstream fuel injection with different stabilization modes.

As expected, the flow is least steady (pressure fluctuations are largest) when the combustion oscillates between the cavity stabilized and jet-wake stabilized locations. The cavity stabilized mode is steadiest with the jet-wake stabilized mode being intermediate. The cavity stabilized mode is the steadiest because the base of the reaction zone is located in a low speed region in the upstream part of the cavity shear layer. This part of the shear layer is relatively steady because it is fixed by the geometry of the cavity. In the jet-wake stabilized mode, the base of the reaction zone must be located in a low speed region of the jet-wake with a proper local equivalence ratio. The wake behind the fuel jet is expected to be much less steady than the recirculation in the fixed geometry cavity and thus the combustion is significantly less steady. As has been noted earlier, the location of the heat release appears to move significantly when oscillating between the two stabilization modes. Thus the pressure fluctuations are highest in this case.

\section{Ramjet Mode Combustion - Downstream Fuel Injection}

The combustion in the Mach 2.2 test section with downstream injection $\left((x / H)_{\text {mainfuel }}=-0.55\right)$ was studied for $T_{0}=1250 \mathrm{~K}, \phi=0.18$ and 0.27 , and $\dot{m}_{\text {cavfuel }} / \dot{m}_{\text {totalfuel }}=0.0$ and 0.10 through floor and rear wall injectors. All conditions achieved main flow ignition with the ramjet mode pre-combustion shock train 
contained in the isolator at all times. The same cases were also run at $T_{0}=1400 \mathrm{~K}$. Some ram-to-scram oscillations were encountered at low $\phi$ and the shock train was not contained for some cases of high $\phi$. These sources of unsteadiness are outside the scope of the current work and thus data from the $T_{0}=1400 \mathrm{~K}$ cases is not presented.

Figure 11 shows the standard deviation of the pressure fluctuations for $T_{0}=1250 \mathrm{~K}$ and Fig. 12 shows average flame luminosity pictures for the same cases. There was no jumping between clearly distinct stabilization locations as in the case of upstream fuel injection, so the luminosity images are averaged over $1000 \mathrm{~ms}$.

Figure 11(b) shows that for $\phi=0.27$, cavity fueling from either location makes the flow significantly more steady. The luminosity images for these cases give insight into the reason for the difference in steadiness. For no cavity fueling as shown in Fig. 12(d), the combustion appears to be in the jet-wake stabilized mode. The shape and location of the reaction zone with respect to the fuel injector is very similar to that seen for the upstream injection, jet-wake stabilized case shown in Fig. 7(b). Additionally the magnitude of the pressure fluctuations are similar to the upstream injection, jet-wake stabilized case shown in Fig. 10(b). Thus, although the reaction zone is located over the cavity, the cavity does not appear to play a major role in the stabilization for this case.

For $\phi=0.27$ with cavity fueling, Figs. $12(\mathrm{e}),(\mathrm{f})$ show that the reaction zone extends into the upstream part of the cavity. As stated in Section B 1, this is a relatively steady area of low speed flow. Thus the steady combustion in this area provides heat and radicals to the main flow reaction which appears to be primarily jet-wake stabilized (by shape and location). Therefore this hybrid stabilization is more steady than pure jet-wake stabilization, but not as steady as pure cavity stabilization. It can be seen that the cavity shear layer reaction is significantly stronger for cavity floor fueling, which is likely why this configuration produced a slightly more steady flow field. Pure cavity stabilized combustion, such as found for upstream main fuel injection, was not found for downstream main fuel injection. It is expected that cavity stabilized combustion is burning in a premixed fashion. For downstream fuel injection there is not enough distance between the injection location and the cavity leading edge for this premixing to occur.

The same basic trends in combustion stabilization and steadiness can be seen for the $\phi=0.18$ case. In this case though, the difference in steadiness with and without cavity fueling is significantly less than for the $\phi=0.27$ case. Figure 12(a) shows that for no cavity fueling, the reaction extends further upstream in the cavity shear layer for $\phi=0.18$ than for $\phi=0.27$. Thus the cavity is likely playing a role in stabilizing this combustion and making it more steady. The reason for this is that the main fuel jet penetration is less for the lower equivalence ratio, so there may be more main fuel entrained into the cavity for this case. With cavity fueling, shown in Fig. 12(b),(c) the reaction zone again extends into the upstream, steadiest part of the cavity shear layer. The pressure fluctuations then are moderately reduced as shown in Fig. 11(a). (Note that $\sigma_{P_{w} / P_{0, i}}$ for cavity rear wall and floor cavity fueling is very similar at all points except at $(x / H)=-8.0$. At this location the pressure fluctuations are negligible for the rear wall cavity fueling case but not for the floor cavity fueling case. This point is an artifact of monitoring a relatively small number of locations and should not be used to conclude that the flow was significantly less steady for the floor cavity fueling case. The shock train leading edge extended upstream of this location a few times during the cavity floor fueling test and not for the rear wall fueling test, but the pressure fluctuation magnitudes at other locations were very similar.)

\section{Scramjet Mode Combustion}

Scramjet-mode $\left(M_{i, \text { exit }}>1\right)$ combustion was achieved using the Mach 2.5 test section. For this higher Mach number, more heat can be added to the flow for a given stagnation temperature before thermal choking (and scram-to-ram transition). The shorter isolator on this test section was sufficient to contain the weak scram-mode pre-combustion shock train. To date, scram-mode combustion has been achieved only for cases of high cavity fueling near the lean ignition limit, which result in a low frequency scram-to-ram oscillation. At this condition, the combustion is observed in the high speed movies to be quasi-steady for $\sim 50 \mathrm{~ms}$ in each mode during a cycle. Thus we may compare the scramjet-mode and ramjet-mode images if we assume the structure of the reaction zone during the quasi-steady time is relatively unaffected by the low frequency ram-to-scram oscillations. To obtain fully steady scram-mode combustion in this combustor would require raising $T_{0}$, lowering $\phi$ (while still igniting), moving the heat release further downstream, or some combination of the these.

Figure 13 shows flame luminosity images for ramjet and scramjet mode combustion averaged over 37.5 


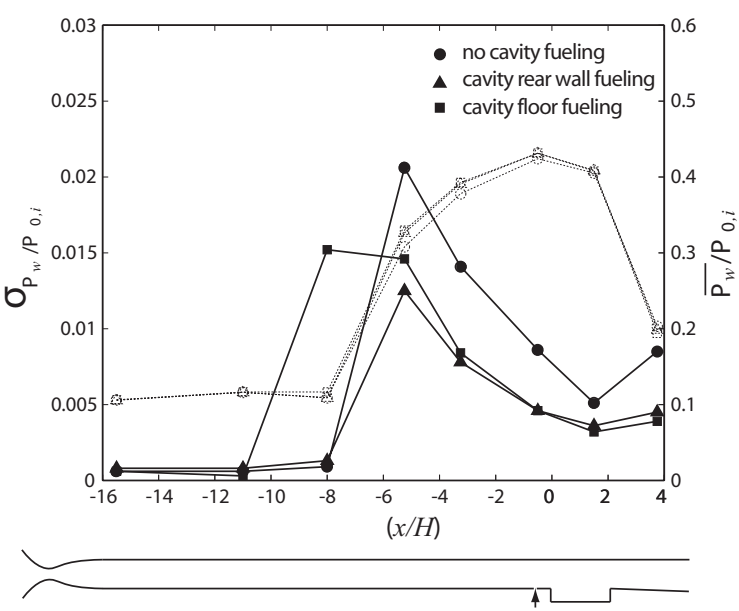

(a) $\phi=0.18, \dot{m}_{\text {cavfuel }} / \dot{m}_{\text {totalfuel }}=0.0$ or 0.10

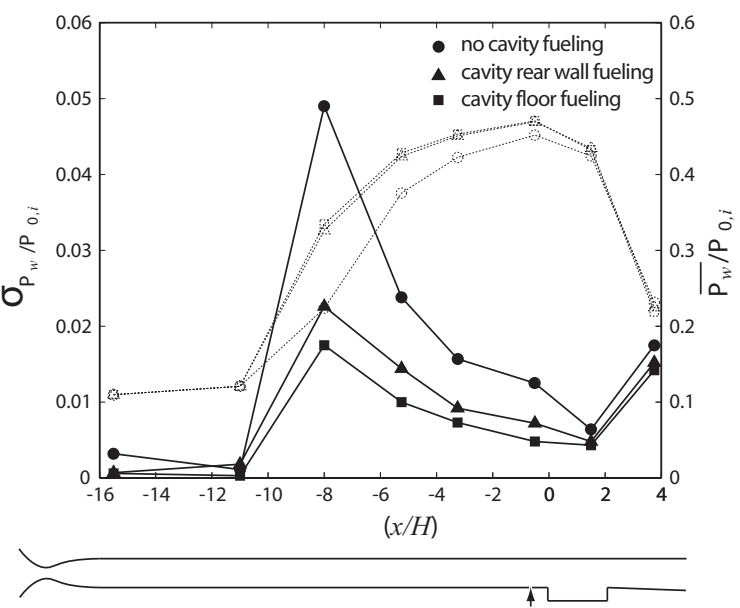

(b) $\phi=0.27, \dot{m}_{\text {cavfuel }} / \dot{m}_{\text {totalfuel }}=0.0$ or 0.10

Figure 11. Wall pressure standard deviation (solid symbols) and average (open symbols) for downstream fuel injection with $T_{0}=1250 \pm 30 \mathrm{~K}$.

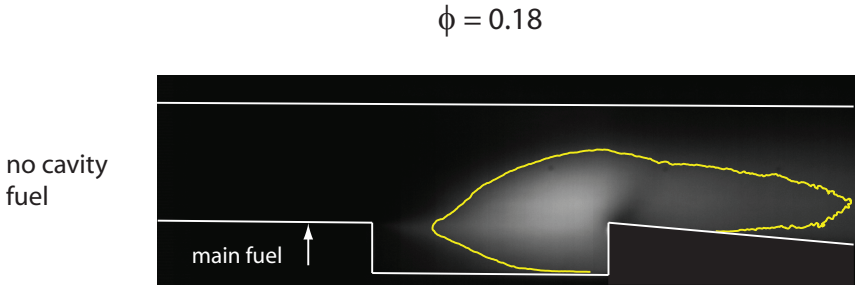

(a)

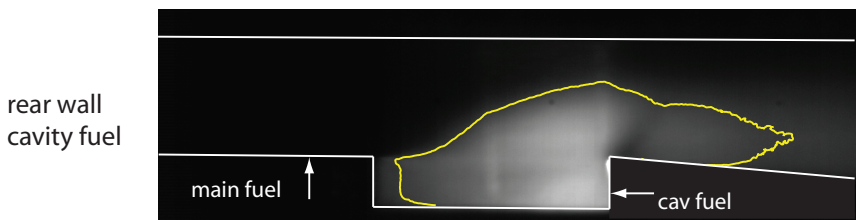

(b)

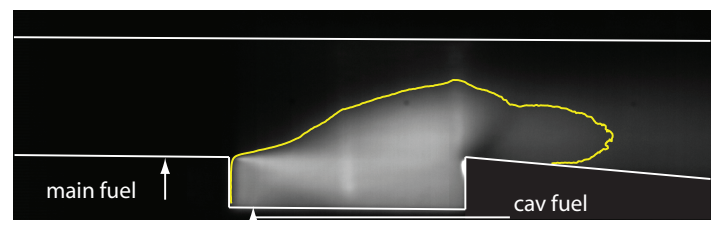

(c)

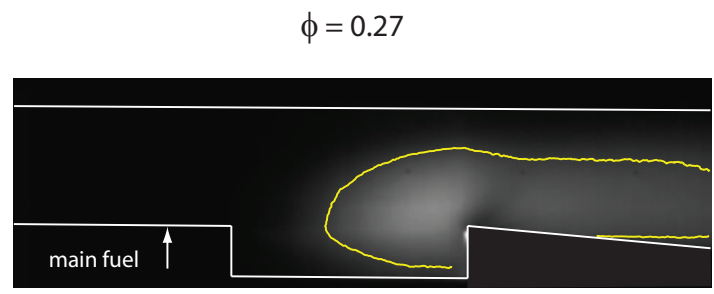

(d)

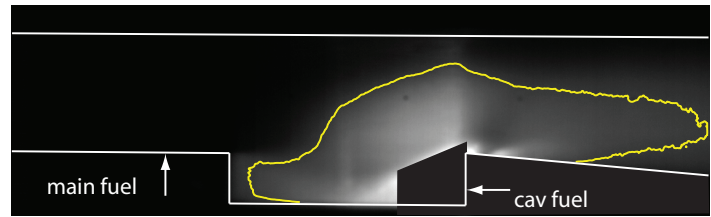

(e)

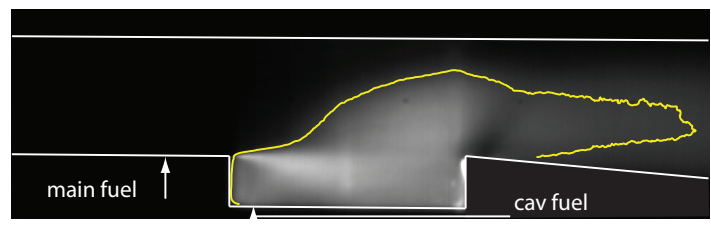

(f)

Figure 12. Flame luminosity images averaged over $1000 \mathrm{~ms}$ for downstream main fuel injection. $T_{0}=1250 \pm 30 \mathrm{~K}$, $\dot{m}_{\text {cavfuel }} / \dot{m}_{\text {totalfuel }}=0.10$ for cases with cavity fueling. Yellow line is isoluminosity contour. Image (e) is blacked out in the rear corner of the cavity due to buildup on the window which was glowing brightly. 
ms during which the combustion is quasi-steady. The combustion mode was determined from $P_{w} / P_{0, i}$ at the last measurement location in the isolator at $(x / H)=-3.25$. The Mach number at this location was estimated using the 1-D impulse function method given by Heiser and Pratt. ${ }^{4,5}$ As expected from theory, there was a large jump in $M_{i, \text { exit }}$ at ram-to-scram transition. For the case shown in Fig. 13, the scramjet mode $M_{i, \text { exit }}$ was calculated to be approximately 1.43 from $P_{w} / P_{0, i}=0.15$ and the ramjet mode $M_{i, \text { exit }}$ to be approximately 0.70 from $P_{w} / P_{0, i}=0.35$. It can be seen from Fig. 13 that the reaction zone shape is significantly different between ramjet and scramjet mode operation. It is interesting to see that scramjet mode reaction zone looks quite similar to the cavity stabilized, ramjet mode reaction zone. The flame base is anchored in the cavity shear layer and it spreads into the supersonic flow at an approximately constant angle of 18 degrees. The ramjet mode reaction zone expectedly looks similar to that found in the Mach 2.2 test section for similar conditions.

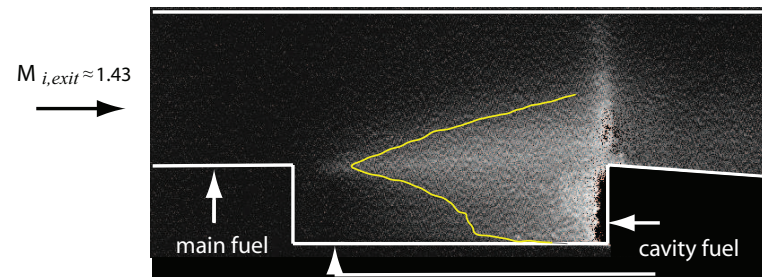

(a) Scramjet mode (supersonic) combustion. $M_{i, \text { exit }} \approx 1.43$ from pressure data.

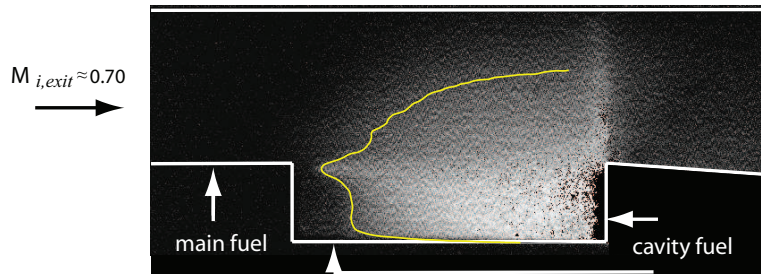

b) Ramjet mode (subsonic) combustion. $M_{i, \text { exit }} \approx 0.70$ from pressure data.

Figure 13. Flame luminosity images averaged over $37.5 \mathrm{~ms}$ for same run in Mach 2.5 test section. $T_{0}=1350 K$, $\phi=0.34, \dot{m}_{\text {cavfuel }} / \dot{m}_{\text {totalfuel }}=0.23$. Yellow line shows isoluminosity contour. Vertical white streak above cavity trailing edge in images is an artifact of camera overexposure at cavity trailing edge and is not from flame luminosity.

\section{Conclusions}

Properties of a laboratory dual-mode scramjet combustor are reported for a range of Mach numbers, fuel injection locations, total fuel flow rates, cavity fueling rates, and stagnation temperatures. The stagnation temperatures studied correspond to the low end of dual-mode scramjet flight Mach numbers where a wall cavity pilot flame is needed to assist in ignition and combustion stabilization.

1. Combustion of the main fuel jet was observed to occur in both the ramjet and scramjet modes. The isolator exit mach number $\left(M_{i, e x i t}\right)$ was estimated from the wall static pressure.

2. Two distinct combustion stabilization modes were found for ramjet operation with upstream main fuel injection: jet-wake stabilized and cavity stabilized. Cavity stabilized combustion was anchored at the leading edge of the cavity shear layer and spread into the main flow at an approximately constant angle. Jet-wake stabilized combustion was located in the wake of the fuel injection jet, a short distance downstream. For main fuel injection close to the cavity, the stabilization location of these two modes overlapped, and so a hybrid stabilization mode existed. For scramjet operation, the reaction zone appeared similar to the cavity stabilized mode.

3. The fraction of time spent in each stabilization mode was measured for a range of conditions and found to depend primarily on $T_{0}$ (for ramjet operation with upstream main fuel injection). The combustion was primarily in the jet-wake stabilized mode at high $T_{0}$ and in the cavity-stabilized mode at low $T_{0}$. There was an intermediate range of $T_{0}$ for which the combustion oscillated between the two modes.

4. Wall pressure measurements showed significant differences in the steadiness of the flow field for different combustion stabilization modes. For upstream main fuel injection, the cavity stabilized mode was the steadiest, followed by the jet-wake stabilized mode, and the intermediate, oscillating mode. For downstream main fuel injection, the steadiness of the flow field was dependent on the cavity fueling. With no cavity fueling the pressure fluctuations were approximately the same magnitude as for jet-wake stabilized combustion. Cavity fueling created a steady source of radicals which led to significantly steadier combustion.

5. The lean main flow ignition limit was measured for a range of cavity fueling rates. The minimum $\phi$ for ignition dropped by approximately $15 \%$ when increasing $\dot{m}_{\text {cavity fuel }} / \dot{m}_{\text {total fuel }}$ from 0.02 to 0.07 . There 
was little effect realized by further increasing $\dot{m}_{\text {cavity fuel }} / \dot{m}_{\text {totalfuel }}$ to 0.21 .

6. The flame luminosity during the ignition process was resolved by high speed movies taken at 7100 Hz. For the conditions of this study, the ignition process always begins in the cavity and the reaction zone then moves to the stabilization location (if different). Therefore, even for conditions where the cavity does not play a significant role in the combustion stabilization (such as the jet-wake stabilized mode), the cavity remains crucial to the ignition process. At stagnation temperatures significantly greater than the maximum value that was studied $(1400 \mathrm{~K})$, it is expected that the role of the cavity will diminish compared with the role of auto-ignition.

\section{References}

${ }^{1}$ Ben-Yakar, A. and Hanson, R. K., "Cavity flame-holders for ignition and flame stabilization in scramjets: an overview," Journal of Propulsion and Power, Vol. 17, No. 4, 2001, pp. 869-877.

${ }^{2}$ Mathur, T., Gruber, M., Jackson, K., Donbar, J., Donaldson, W., Jackson, T., and Billig, F., "Supersonic combustion experiments with a cavity based fuel injector," Journal of Propulsion and Power, Vol. 17, No. 6, 2001, pp. 1305-1312.

${ }^{3}$ Gruber, M. R., Donbar, J. M., Carter, C. D., and Hsu, K.-Y., "Mixing and combustion studies using cavity-based flameholders in a supersonic flow," Journal of Propulsion and Power, Vol. 20, No. 5, 2004, pp. 769-778.

${ }^{4}$ Heiser, W. H. and Pratt, D. T., Hypersonic Airbreathing Propulsion, AIAA Education Series, AIAA, 1994.

${ }^{5}$ Curran, E. T., Heiser, W. H., and Pratt, D. T., "Fluid phenomena in scramjet combustion systems," Annual Review of Fluid Mechanics, Vol. 28, 1996, pp. 323-360.

${ }^{6}$ Heiser, W. H. and Pratt, D. T., "Aerothermodynamics of the dual-mode combustion system," Scramjet Propulsion, edited by E. T. Curran and S. N. B. Murthy, AIAA, Virginia, 2000, pp. 569-595.

${ }^{7}$ Billig, F. S., "Research on supersonic combustion," Journal of Propulsion and Power, Vol. 9, No. 4, 1993, pp. 499-514.

${ }^{8}$ McMillin, B. K., Seitzman, J. M., and Hanson, R. K., "Comparison of NO and OH planar fluorescence temperature measurements in scramjet model flowfields," AIAA Journal, Vol. 32, No. 10, 1994, pp. 1945-1952.

${ }^{9} \mathrm{Yu}, \mathrm{K} . \mathrm{H} ., \mathrm{Wilson}, \mathrm{K} . \mathrm{J}$. , and Schadow, K. C., "Effect of flame-holding cavities on supersonic-combustion performance," Journal of Propulsion and Power, Vol. 17, No. 6, 2001, pp. 1287-1295.

${ }^{10}$ Donbar, J. M., Gruber, M. R., Jackson, T. A., Carter, C. D., and Mathur, T., "OH planar laser-induced fluorescence imaging in a hydrocarbon-fueled scramjet combustor," Proceedings of the Combustion Institute, Vol. 28, 2001, pp. 679-687.

${ }^{11}$ Lin, K.-C., Tam, C.-J., Boxx, I., Carter, C., Jackson, K., and Lindsey, M., "Flame characteristics and fuel entrainment inside a cavity flame holder in a scramjet combustor," Joint Propulsion Conference 8 Exhibit, AIAA/ASME/SAE/ASEE, 2007.

${ }^{12}$ Yu, G., Li, J., Zhao, J., Yue, L., Chang, X., and Sung, C.-J., "An experimental study of kerosene combustion in a supersonic model combustor using effervescent atomization," Proceedings of the Combustion Institute, Vol. 30, 2005, pp. 28592866.

${ }^{13}$ Fan, X., Yu, G., Li, J., Zhang, X., and Sung, C.-J., "Investigation of vaporized kerosene injection and combustion in a supersonic model combustor," Journal of Propulsion and Power, Vol. 22, No. 1, 2006, pp. 103-110.

${ }^{14} \mathrm{Yu}$, G., Li, J. G., Zhang, X. Y., Chen, L. H., Han, B., and Sung, C. J., "Experimental investigation of flameholding mechanism and combustion performance in hydrogen-fueled supersonic combustors," Comb. Science and Technology, Vol. 174, 2002, pp. 1-27.

${ }^{15}$ Mitani, T. and Izumikawa, M., "Criteria for flame holding in H2-fueled scramjet engines," Proceedings of the Combustion Institute, Vol. 28, 2001, pp. 689-695.

${ }^{16}$ OByrne, S., Stotz, I., Neely, A. J., Boyce, R. R., Mudford, N. R., and Houwing, A. F. P., "OH PLIF imaging of supersonic combustion using cavity injection," International Space Planes and Hypersonics Systems and Technologies Conference, AIAA/CIRA, 2005.

${ }^{17}$ Baurle, R. A. and Eklund, D. R., "Analysis of dual-mode hydrocarbon scramjet operation at mach 4-6.5," Journal of Propulsion and Power, Vol. 18, No. 5, 2002, pp. 990-1002.

${ }^{18}$ Ben-Yakar, A. and Hanson, R. K., "Experimental investigation of flame-holding capability of hydrogen transverse jet in supersonic cross-flow," Proceedings of the Combustion Institute, Vol. 27, 1999, pp. 2173-2180.

${ }^{19}$ Kutschenreuter, P., "Supersonic flow combustors," Scramjet Propulsion, edited by E. T. Curran and S. N. B. Murthy, AIAA, Virginia, 2000, pp. 513-568.

${ }^{20} \mathrm{McDaniel}$, J. C. and Graves, J., "Laser-induced-fluorescence visualization of transverse gaseous injection in a nonreacting supersonic combustor," Journal of Propulsion and Power, Vol. 4, No. 6, 1988, pp. 591-597.

${ }^{21}$ Rasmussen, C. C., Dhanuka, S. K., and Driscoll, J. F., "Visualization of flameholding mechanisms in a supersonic combustor using PLIF," Proceedings of the Combustion Institute, Vol. 31, 2007, pp. 2505-2512.

${ }^{22}$ Rasmussen, C. C., Driscoll, J. F., Hsu, K.-Y., Donbar, J. M., Gruber, M. R., and Carter, C. D., "Stability limits of cavity-stabilized flames in supersonic flow," Proceedings of the Combustion Institute, Vol. 30, 2005, pp. $2825-2833$.

${ }^{23}$ Driscoll, J. and Rasmussen, C. C., "Correlation and analysis of blowout limits of flames in high-speed airflows," Journal of Propulsion and Power, Vol. 21, No. 6, 2005, pp. 1035-1044. 